\title{
The Skin Tissue of the Human Head Subjected to Thermal Diffusion
}

\author{
Eman A. N. Al-Lehaibi \\ Mathematics Department, College of Science and Arts-Sharoura, Najran University, Najran, Saudi Arabia \\ Correspondence should be addressed to Eman A. N. Al-Lehaibi; dremanallehaibi@gmail.com
}

Received 26 June 2017; Revised 14 November 2017; Accepted 8 January 2018; Published 31 January 2018

Academic Editor: Elena Benvenuti

Copyright (C) 2018 Eman A. N. Al-Lehaibi. This is an open access article distributed under the Creative Commons Attribution License, which permits unrestricted use, distribution, and reproduction in any medium, provided the original work is properly cited.

\begin{abstract}
We consider a problem of skin tissue of the human head subjected to thermal diffusion with relaxation time. The bounding surface of the tissue of the human head is subjected to a thermal shock. The chemical potential is also assumed to be a known function of time on the bounding plane. Laplace transform techniques are used and the results are obtained numerically using a numerical method for the inversion of the Laplace transform based on Tzou method. The temperature distribution and the concentration distribution are obtained and represented in figures. According to the results, the values of the time and the distance have significant effects on the temperature increment and the concentration. The values of the temperature increment and the concentration increase when the time increases and decrease when the distance increases.
\end{abstract}

\section{Introduction}

Biomechanics is the area of science where the laws, principles, and methods of mechanics are applied to the structure and function of the human body. Mechanics can be divided into two categories: statics, which is the study of stationary objects, and dynamics, which is the study of moving objects [1].

Some human trial studies have expressed that, in the short term, being subjected to cellular phones frequencies can cause such problems like exciting the brain cells when subjected to a wave [1], the possible occurrence of cataracts with continuous exposure weakening the neural behavioral and cognitive functioning, and possibly a disruption in the functionality of the nervous system [1]. Lindholm et al. [2] conducted a human trial to see the effects of short term radio frequency when the electromagnetic fields are subjected to preadolescents.

Ferreri et al. studied the mobile phone emissions and human brain excitability [3] and Keetley et al. studied the neuropsychological squeal of digital mobile phone exposure in humans [4], while Lin discussed the cataracts and personal communication radiation [5]. The effects of electromagnetic radiation of mobile phones on the central nervous system have been studied by Hossmann and Hermann [6] and the thermal effects of radiation from cellular telephones have been studied by Wainwright [7].

The most important work regarding specific absorption rate and temperature distributions in human head subjected to mobile phone radiation at different frequencies was introduced by Wessapan et al. [8]. Elwassif et al. constructed the bioheat transfer model of deep brain stimulation-induced temperature changes [9]. Ley and Bayazitoglu analyzed the brain temperature distribution during deep hypothermic circulatory arrest in humans [10] and got the effect of physiology on the temperature distribution of a layered head with external convection [1].

The thermal wave model of bioheat transfer (TWMBT) equation is an energy balance equation that includes the heat caused by conduction, convection, metabolic heat generation, and the heat produced by radiation due to the cellular frequency [11]. The model incorporates a relaxation time to account for the lag time it takes for the radio frequency wave to respond to the heat penetrating through the tissue, that is, heat flux associated with the tissues [12, 13]. Biological experimental studies have shown that this value can range from 15 to $30 \mathrm{~s}[12,14-20]$. An additional relaxation time accommodating the phase lag of the temperature gradient is analytically studied. 


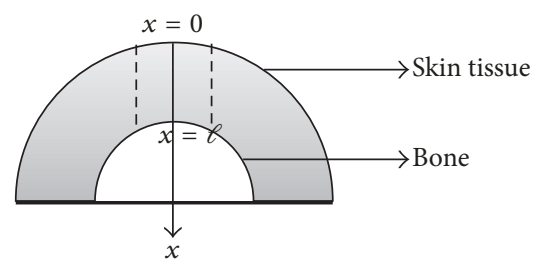

FIGURE 1: The human head.

Morimoto et al. [21] studied the time constants of the temperature elevations in human head and body models exposed to simulated radiation from dipole antennas, electromagnetic beams, and plane waves within frequency range considered to be from 1 to $30 \mathrm{GHz}$. Tang et al. discussed the thermal and vibrational characterization of human skin to find suitable and reproducible biomarkers for further clinical studies on intrinsic and extrinsic aging of dermis [22].

\section{Formulation of the Problem}

We consider a small bounded cross section of the skin tissue of the human head occupies the region $0 \leq x \leq \ell$ subjected to thermal diffusion (such as a gas) in the upper plane of the skin tissue $x=0$ as in Figure 1, and this tissue is initially quiescent.

The heat transfer in living tissue is accompanied by blood perfusion and metabolic heat generation; the bioheat equation takes the following form [4]:

$$
\begin{aligned}
& K \frac{\partial^{2} T_{s}}{\partial x^{2}} \\
& =\left(\frac{\partial}{\partial t}+\tau_{1} \frac{\partial^{2}}{\partial t^{2}}\right)\left(\rho c_{e} T_{s}+\alpha C\right) \\
& \quad+\left(1+\tau_{1} \frac{\partial}{\partial t}\right)\left(\rho_{p} \omega_{p} c_{p}\left(T_{s}-T_{b}\right)-Q_{\text {met }}-Q_{\text {out }}\right),
\end{aligned}
$$

where $T_{s}=T_{s}(x, t)$ is the temperature of the tissue, $T_{b}$ is the blood temperature (constant), $K$ is the thermal conductivity, $\rho$ is the density of the skin tissue, $\rho_{p}$ is the blood mass density, $c_{p}$ is the specific heat of the blood, $c_{e}$ is the specific heat of the skin tissue, $\omega_{p}$ is the blood perfusion rate, $Q_{\text {out }}$ is the external heat source, $Q_{\text {met }}$ is the heat source due to metabolic heating, $\alpha$ is a measure of thermodiffusion effect, $\tau_{1}$ is the relaxation time of the skin tissue, and $C=C(x, t)$ is the concentration of the diffusive material in the skin tissue.

The diffusion equations take the form

$$
D \frac{\partial^{2} P}{\partial x^{2}}=\left(\frac{\partial}{\partial t}+\tau_{2} \frac{\partial^{2}}{\partial t^{2}}\right) C,
$$

where $\tau_{2}$ is the diffusion relaxation time, $D$ is the diffusion coefficient, and $P=P(x, t)$ is the chemical potential which satisfies

$$
P=\beta C-\alpha\left(T_{s}-T_{p}\right)
$$

where $\beta$ is a measure of diffusive effect.
To simplify the equations in (1)-(3), we will use the following nondimension variables:

$$
\begin{aligned}
x^{\prime} & =\sqrt{\frac{\omega_{p} \rho_{p} c_{p}}{K}} x, \\
\left(t^{\prime}, \tau_{1}^{\prime}, \tau_{2}^{\prime}\right) & =\frac{\omega_{p} \rho_{p} c_{p}}{\rho c}\left(t, \tau_{1}, \tau_{2}\right), \\
P^{\prime} & =\frac{P}{\alpha T_{p}}, \\
C^{\prime} & =\frac{\beta}{\alpha T_{p}} C, \\
\theta & =\frac{T_{s}-T_{p}}{T_{p}}, \\
\left(Q_{\text {met }}^{\prime}, Q_{\text {out }}^{\prime}\right) & =\frac{\left(Q_{\text {met }}, Q_{\text {out }}\right)}{\omega_{p} \rho_{p} c_{p} T_{p}} .
\end{aligned}
$$

After applying the dimensionless variables, (1)-(3) take the forms

$$
\begin{aligned}
\frac{\partial^{2} \theta}{\partial x^{2}}= & \left(\frac{\partial}{\partial t}+\tau_{1} \frac{\partial^{2}}{\partial t^{2}}\right)\left(\theta+a_{1} C\right) \\
& +\left(1+\tau_{1} \frac{\partial}{\partial t}\right)\left(\theta-Q_{\text {met }}-Q_{\text {out }}\right), \\
\frac{\partial^{2} P}{\partial x^{2}}= & a_{2}\left(\frac{\partial}{\partial t}+\tau_{2} \frac{\partial^{2}}{\partial t^{2}}\right) C, \\
P= & C-\theta
\end{aligned}
$$

where $a_{1}=\alpha^{2} / \rho \beta c$ and $a_{2}=K / \rho \beta c D$.

We dropped the prime for simplicity.

We will consider the tissue has no external heat source $\left(Q_{\text {out }}=0\right)$ and the heat source due to metabolic heating $Q_{\text {met }}$ is constant; then we get

$$
\begin{aligned}
\frac{\partial^{2} \theta}{\partial x^{2}}= & \left(\frac{\partial}{\partial t}+\tau_{1} \frac{\partial^{2}}{\partial t^{2}}\right)\left(\theta+a_{1} C\right) \\
& +\left(1+\tau_{1} \frac{\partial}{\partial t}\right)\left(\theta-Q_{\text {met }}\right) .
\end{aligned}
$$

By eliminating $P$ between (6) and (7), we obtain

$$
\frac{\partial^{2} C}{\partial x^{2}}-\frac{\partial^{2} \theta}{\partial x^{2}}=a_{2}\left(\frac{\partial}{\partial t}+\tau_{2} \frac{\partial^{2}}{\partial t^{2}}\right) C .
$$

We will apply Laplace transform on (6) and (8) which is defined as

$$
\bar{f}(x, s)=\int_{0}^{\infty} f(x, t) e^{-s t} d t, \quad s>0,
$$

where $\left.C(x, t)\right|_{t=0}=\left.\theta(x, t)\right|_{t=0}=\partial C(x, t) /\left.\partial t\right|_{t=0}=$ $\partial \theta(x, t) /\left.\partial t\right|_{t=0}=0$. 
Hence, we get

$$
\begin{aligned}
\frac{\partial^{2} \bar{\theta}}{\partial x^{2}}= & \left(1+\tau_{1} s\right)(1+s) \bar{\theta}+a_{1}\left(s+\tau_{1} s^{2}\right) \bar{C} \\
& -\frac{Q_{\text {met }}}{s}, \\
\frac{\partial^{2} \bar{C}}{\partial x^{2}}-\frac{\partial^{2} \bar{\theta}}{\partial x^{2}}= & a_{2}\left(s+\tau_{2} s^{2}\right) \bar{C} .
\end{aligned}
$$

By eliminating $\bar{\theta}$ between the equations in (11), we obtain

$$
\left[\frac{\partial^{4}}{\partial x^{4}}-\left(\alpha_{1}+\alpha_{2}+\alpha_{3}\right) \frac{\partial^{2}}{\partial x^{2}}+\alpha_{1} \alpha_{3}\right] \bar{C}=0,
$$

and by eliminating $\bar{C}$ between the equations in (11), we get

$$
\left[\frac{\partial^{4}}{\partial x^{4}}-\left(\alpha_{1}+\alpha_{2}+\alpha_{3}\right) \frac{\partial^{2}}{\partial x^{2}}+\alpha_{1} \alpha_{3}\right] \bar{\theta}=\alpha_{4},
$$

where $\alpha_{1}=\left(1+\tau_{1} s\right)(1+s), \alpha_{2}=a_{1}\left(s+\tau_{1} s^{2}\right), \alpha_{3}=a_{2}(s+$ $\left.\tau_{2} s^{2}\right), \alpha_{4}=\alpha_{3} Q_{\text {met }} / s$. forms

We can write the general solutions of (12) and (13) in the

$$
\begin{aligned}
\bar{\theta}(x, s)= & \gamma_{1} e^{\lambda_{1} x}+\gamma_{2} e^{\lambda_{2} x}+\beta_{1} e^{-\lambda_{1} x}+\beta_{2} e^{-\lambda_{2} x}+\frac{\alpha_{4}}{M}, \\
\bar{C}(x, s)= & \left(\frac{\lambda_{1}^{2}-\alpha_{3}}{\lambda_{1}^{2}}\right) \gamma_{1} e^{\ell_{1} x}+\left(\frac{\lambda_{2}^{2}-\alpha_{3}}{\lambda_{2}^{2}}\right) \gamma_{2} e^{\lambda_{2} x} \\
& +\left(\frac{\lambda_{1}^{2}-\alpha_{3}}{\lambda_{1}^{2}}\right) \beta_{1} e^{-\lambda_{1} x} \\
& +\left(\frac{\lambda_{2}^{2}-\alpha_{3}}{\lambda_{2}^{2}}\right) \beta_{2} e^{-\lambda_{2} x},
\end{aligned}
$$

where $\gamma_{1}=\gamma_{1}(s), \gamma_{2}=\gamma_{2}(s), \beta_{1}=\beta_{1}(s), \beta_{2}=\beta_{2}(s)$ are parameters and $\pm \lambda_{1}(s), \pm \lambda_{2}(s)$ are the roots of the characteristic equation

$$
\lambda^{4}-L \lambda^{2}+M=0
$$

where $L=\left(\alpha_{1}+\alpha_{2}+\alpha_{3}\right), M=\alpha_{1} \alpha_{3}$.

To get the parameters $\gamma_{1}, \gamma_{2}, \beta_{1}, \beta_{2}$, we will consider the upper plane of the tissue $x=0$ is subjected to thermal and chemical potential shock which depends on time only as follows:

$$
\begin{aligned}
& \theta(0, t)=f(t), \\
& \theta(\ell, t)=0, \\
& P(0, t)=g(t), \\
& P(\ell, t)=0 .
\end{aligned}
$$

Applying Laplace transform on conditions (16), we get

$$
\begin{aligned}
& \bar{\theta}(0, s)=\bar{f}(s), \\
& \bar{P}(0, s)=\bar{g}(s) .
\end{aligned}
$$

By using (7) and (17), we get

$$
\bar{C}(0, s)=\bar{f}(s)+\bar{g}(s) .
$$

Applying the conditions in (17) and (18) on (14), we obtain the following system of linear equations:

$$
\begin{aligned}
& \gamma_{1}+\gamma_{2}+\beta_{1}+\beta_{2}=\bar{f}(s)-\frac{\alpha_{4}}{M}, \\
& \left(\frac{\lambda_{1}^{2}-\alpha_{3}}{\lambda_{1}^{2}}\right) \lambda_{1}+\left(\frac{\lambda_{2}^{2}-\alpha_{3}}{\lambda_{2}^{2}}\right) \gamma_{2}+\left(\frac{\lambda_{1}^{2}-\alpha_{3}}{\lambda_{1}^{2}}\right) \beta_{1} \\
& \quad+\left(\frac{\lambda_{2}^{2}-\alpha_{3}}{\lambda_{2}^{2}}\right) \beta_{2}=\bar{f}(s)+\bar{g}(s) \\
& \lambda_{1} \gamma_{1} e^{\lambda_{1} \ell}+\lambda_{2} \gamma_{2} e^{\lambda_{2} \ell}-\lambda_{1} \beta_{1} e^{-\lambda_{1} \ell}-\lambda_{2} \beta_{2} e^{-\lambda_{2} \ell}=0 \\
& \left(\frac{\lambda_{1}^{2}-\alpha_{3}}{\lambda_{1}}\right) \gamma_{1} e^{\lambda_{1} \ell}+\left(\frac{\lambda_{2}^{2}-\alpha_{3}}{\lambda_{2}}\right) \gamma_{2} e^{\lambda_{2} \ell} \\
& \quad-\left(\frac{\lambda_{1}^{2}-\alpha_{3}}{\lambda_{1}}\right) \beta_{1} e^{-\lambda_{1} \ell}-\left(\frac{\lambda_{2}^{2}-\alpha_{3}}{\lambda_{2}}\right) \beta_{2} e^{-\lambda_{2} \ell}=0 .
\end{aligned}
$$

By solving the system above, we get

$$
\begin{aligned}
& \gamma_{1}=\frac{\lambda_{1}^{2}\left[\alpha_{3}\left(\alpha_{4} s-\bar{f}(s) M\right)-\lambda_{2}^{2}\left(\alpha_{4} s+\bar{g}(s) M\right)\right]}{\alpha_{3} M\left(\lambda_{2}^{2}-\lambda_{1}^{2}\right)\left(1+e^{2 \ell \lambda_{1}}\right)}, \\
& \gamma_{2}=\frac{\lambda_{2}^{2}\left[\alpha_{3}\left(\alpha_{4} s-\bar{f}(s) M\right)-\alpha_{1}^{2}\left(\alpha_{4} s+\bar{g}(s) M\right)\right]}{\alpha_{3} M\left(\lambda_{1}^{2}-\lambda_{2}^{2}\right)\left(1+e^{2 \ell \lambda_{2}}\right)}, \\
& \beta_{1} \\
& =\frac{\lambda_{1}^{2} e^{2 \ell \lambda_{1}}\left[\alpha_{3}\left(\alpha_{4} s-\bar{f}(s) M\right)-\alpha_{2}^{2}\left(\alpha_{4} s+\bar{g}(s) M\right)\right]}{\alpha_{3} M\left(\lambda_{2}^{2}-\lambda_{1}^{2}\right)\left(1+e^{2 h \lambda_{1}}\right)},
\end{aligned}
$$

$\beta_{2}$

$$
=\frac{\lambda_{2}^{2} e^{2 \ell \lambda_{2}}\left[\alpha_{3}\left(\alpha_{4} s-\bar{f}(s) M\right)-\lambda_{1}^{2}\left(\alpha_{4} s+\bar{g}(s) M\right)\right]}{\alpha_{3} M\left(\lambda_{1}^{2}-\lambda_{2}^{2}\right)\left(1+e^{2 \ell \lambda_{2}}\right)} .
$$

Thus, we have the solution of the problem in the Laplace transform domain in the form

$$
\begin{gathered}
\bar{\theta}(x, s)=\frac{\lambda_{2}^{2}\left[\alpha_{3}\left(\alpha_{4} s-\bar{f}(s) M\right)-\alpha_{1}^{2}\left(\alpha_{4} s+\bar{g}(s) M\right)\right]}{\alpha_{3} M\left(\lambda_{1}^{2}-\lambda_{2}^{2}\right)\left(1+e^{2 \ell \lambda_{2}}\right)} \\
\cdot e^{\lambda_{1} x} \\
+\frac{\lambda_{2}^{2}\left[\alpha_{3}\left(\alpha_{4} s-\bar{f}(s) M\right)-\alpha_{1}^{2}\left(\alpha_{4} s+\bar{g}(s) M\right)\right]}{\alpha_{3} M\left(\lambda_{1}^{2}-\lambda_{2}^{2}\right)\left(1+e^{2 \ell \lambda_{2}}\right)} e^{\lambda_{2} x} \\
+\frac{\lambda_{1}^{2} e^{2 \ell \lambda_{1}}\left[\alpha_{3}\left(\alpha_{4} s-\bar{f}(s) M\right)-\alpha_{2}^{2}\left(\alpha_{4} s+\bar{g}(s) M\right)\right]}{\alpha_{3} M\left(\lambda_{2}^{2}-\lambda_{1}^{2}\right)\left(1+e^{2 h \lambda_{1}}\right)} \\
\cdot e^{-\lambda_{1} x} \\
+\frac{\lambda_{2}^{2} e^{2 \ell \lambda_{2}}\left[\alpha_{3}\left(\alpha_{4} s-\bar{f}(s) M\right)-\lambda_{1}^{2}\left(\alpha_{4} s+\bar{g}(s) M\right)\right]}{\alpha_{3} M\left(\lambda_{1}^{2}-\lambda_{2}^{2}\right)\left(1+e^{2 \ell \lambda_{2}}\right)} \\
\cdot e^{-\lambda_{2} x}+\frac{\alpha_{4}}{M},
\end{gathered}
$$




$$
\begin{aligned}
\bar{C}(x, s)=\left(\frac{\lambda_{1}^{2}-\alpha_{3}}{\lambda_{1}^{2}}\right) \\
. \frac{\lambda_{1}^{2}\left[\alpha_{3}\left(\alpha_{4} s-\bar{f}(s) M\right)-\lambda_{2}^{2}\left(\alpha_{4} s+\bar{g}(s) M\right)\right]}{\alpha_{3} M\left(\lambda_{2}^{2}-\lambda_{1}^{2}\right)\left(1+e^{2 \ell \lambda_{1}}\right)} e^{\lambda_{1} x} \\
+\left(\frac{\lambda_{2}^{2}-\alpha_{3}}{\lambda_{2}^{2}}\right) \\
+\frac{\lambda_{2}^{2}\left[\alpha_{3}\left(\alpha_{4} s-\bar{f}(s) M\right)-\alpha_{1}^{2}\left(\alpha_{4} s+\bar{g}(s) M\right)\right]}{\alpha_{3} M\left(\lambda_{1}^{2}-\lambda_{2}^{2}\right)\left(1+e^{2 \ell \lambda_{2}}\right)} e^{\lambda_{2} x} \\
+\left(\frac{\lambda_{1}^{2}-\alpha_{3}}{\lambda_{1}^{2}}\right) \\
\quad \cdot \frac{\lambda_{1}^{2} e^{2 \ell \lambda_{1}}\left[\alpha_{3}\left(\alpha_{4} s-\bar{f}(s) M\right)-\alpha_{2}^{2}\left(\alpha_{4} s+\bar{g}(s) M\right)\right]}{\alpha_{3} M\left(\lambda_{2}^{2}-\lambda_{1}^{2}\right)\left(1+e^{2 h \lambda_{1}}\right)} \\
\cdot e^{-\lambda_{1} x}+\left(\frac{\lambda_{2}^{2}-\alpha_{3}}{\lambda_{2}^{2}}\right) \\
\quad \cdot \frac{\lambda_{2}^{2} e^{2 \ell \lambda_{2}}\left[\alpha_{3}\left(\alpha_{4} s-\bar{f}(s) M\right)-\lambda_{1}^{2}\left(\alpha_{4} s+\bar{g}(s) M\right)\right]}{\alpha_{3} M\left(\lambda_{1}^{2}-\lambda_{2}^{2}\right)\left(1+e^{2 \ell \lambda_{2}}\right)} \\
\cdot e^{-\lambda_{2} x} .
\end{aligned}
$$

\section{Inverse Laplace Transforms}

To get solutions in the time domain, the Riemann-sum approximation method is used to obtain the numerical results. In this method, any function in Laplace domain can be inverted to the time domain as follows:

$$
h(t)=\frac{e^{\kappa t}}{t}\left[\frac{1}{2} \bar{h}(\kappa)+\operatorname{Re} \sum_{n=1}^{N}(-1)^{n} \bar{h}\left(\kappa+\frac{i n \pi}{t}\right)\right],
$$

where $\operatorname{Re}$ is the real part and $i$ is the imaginary number unit. For faster convergence, many numerical experiments have shown that the value of $\kappa$ satisfies the relation $\kappa t \approx 4.7$.

We considered that the functions on the boundary in (16) will be defined as a shock in the following forms:

$$
f(t)=g(t)=\omega H(t),
$$

where $\omega$ is constant (the intensity of the shock) and $H(t)$ is the Heaviside unit step function.

By using Laplace transform, (23) takes the form

$$
\bar{f}(s)=\bar{g}(s)=\frac{\omega}{s} .
$$

\section{The Numerical Values}

The following properties of a skin tissue are used in the numerical analysis [1-5]:

$$
\rho=1190 \mathrm{~kg} / \mathrm{m}^{3},
$$

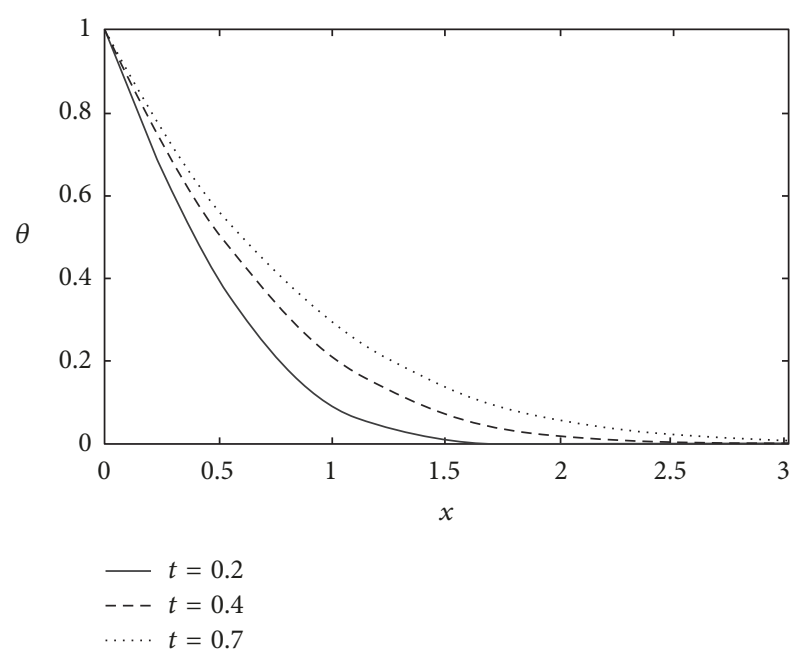

FIGURE 2: The temperature increment distribution at different values of time.

$$
\begin{aligned}
K & =0.235 \mathrm{~W} / \mathrm{mK}, \\
c_{e} & =3600 \mathrm{~J} / \mathrm{kg} \mathrm{K}, \\
\rho_{p} & =1060 \mathrm{~kg} / \mathrm{m}^{3}, \\
c_{p} & =3770 \mathrm{~J} / \mathrm{kg} \mathrm{K} \\
\omega_{p} & =0.5 \mathrm{~kg} / \mathrm{m}^{3} \mathrm{~s}, \\
Q_{m} & =33800 \mathrm{~W} / \mathrm{m}^{3}, \\
q_{o} & =5000 \mathrm{~W} / \mathrm{m}^{3}, \\
T_{p} & =310 \mathrm{~K}, \\
\ell & =0.002 \mathrm{~m}, \\
D & =0.85 \times 10^{-8}, \\
\alpha & =1.2 \times 10^{4}, \\
\beta & =0.9 \times 10^{6}, \\
Q_{\mathrm{met}} & =5.46 \times 10^{-5}, \\
\tau_{1} & =0.002, \\
\tau_{2} & =0.02, \\
a_{1} & =32.098, \\
a_{2} & =7.171 \times 10^{-6} .
\end{aligned}
$$

Figures 2 and 3 represent the temperature increment distribution and the concentration distribution, respectively, with a wide range of the thickness of the layer of the tissue when $0 \leq x \leq 3$ and at different values of time $t=$ $(0.2,0.4,0.7)$. Those figures show that the value of the time has a significant effect on the temperature increment and 


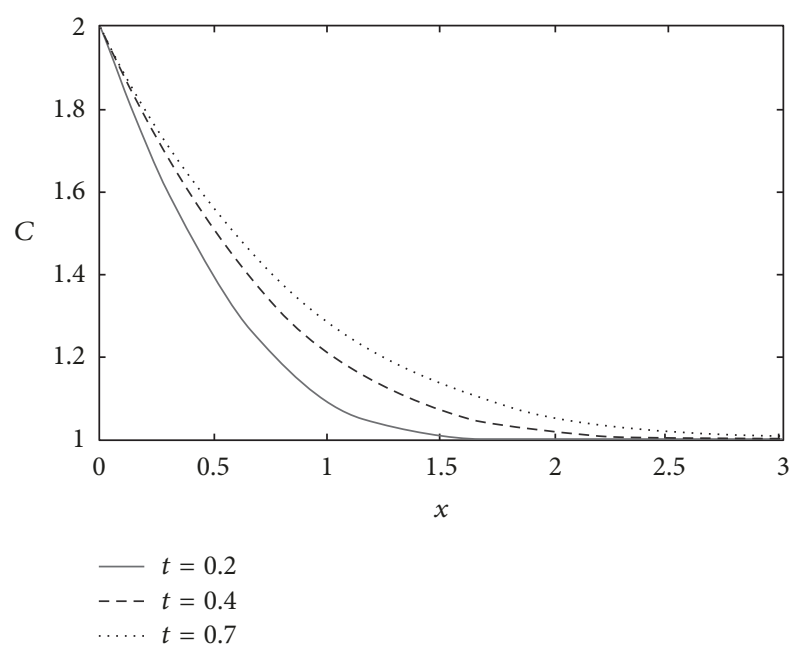

FIGURE 3: The concentration distribution at different values of time.

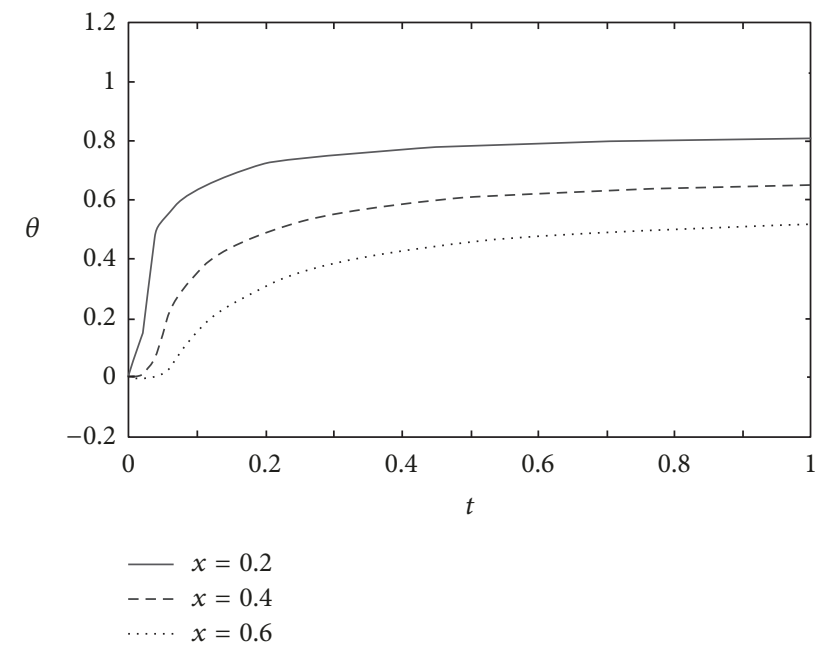

FIGURE 4: The temperature increment distribution at different values of distance.

the concentration. The values of the temperature increment and the concentration increase when the time increases and decrease when the distance increases. The thermal and the concentration waves have finite speeds of wave propagation which agrees with the real physical behavior.

Figures 4 and 5 represent the temperature increment distribution and the concentration distribution, respectively, with a wide range of the time when $0 \leq t \leq 1.0$ and at different values of distance $x=(0.2,0.4,0.6)$. Those figures show that the value of the distance has a significant effect on the temperature increment and the concentration. The values of the temperature increment and the concentration increase when the distance decreases and go to the steady state position when the time increases. Moreover, the steady state positions start first in the nearest distance. The steady states of the thermal wave and the concentration wave occur almost at the same instance.

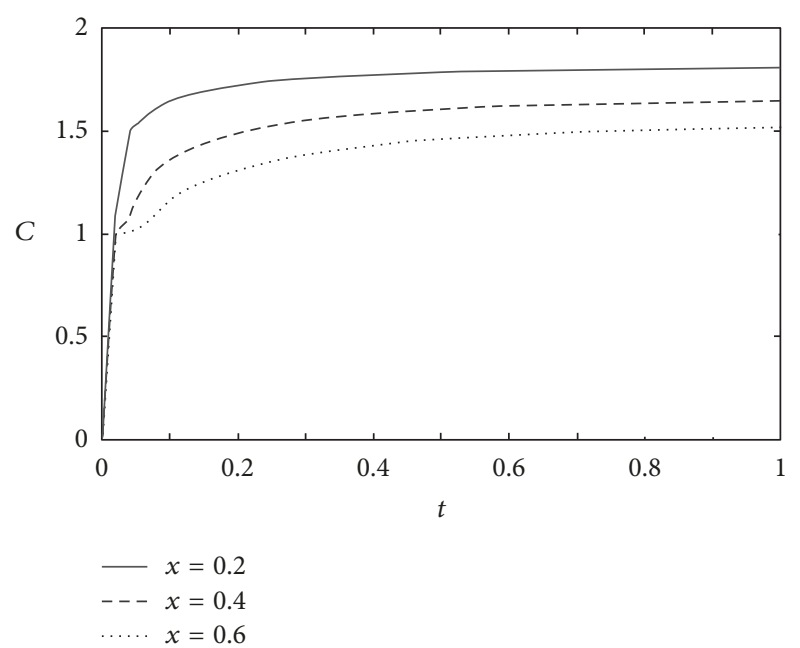

FIGURE 5: The concentration distribution at different values of distance.

\section{Conflicts of Interest}

The funding mentioned in Acknowledgments did not lead to any conflicts of interest regarding the publication of this manuscript.

\section{Acknowledgments}

The author is grateful for the support and the funding for this work provided by Deanship of Scientific Research at Najran University, Saudi Arabia (Grant no. NU/ESCI/15/042).

\section{References}

[1] T. K. Tullius and Y. Bayazitoglu, "Analysis of relaxation times on the human head using the thermal wave model," International Journal of Heat and Mass Transfer, vol. 67, pp. 1007-1013, 2013.

[2] H. Lindholm, T. Alanko, H. Rintamäki et al., "Thermal effects of mobile phone RF fields on children: a provocation study," Progress in Biophysics and Molecular Biology, vol. 107, no. 3, pp. 399-403, 2011.

[3] F. Ferreri, G. Curcio, P. Pasqualetti, L. De Gennaro, R. Fini, and P. M. Rossini, "Mobile phone emissions and human brain excitability," Annals of Neurology, vol. 60, no. 2, pp. 188-196, 2006.

[4] V. Keetley, A. W. Wood, J. Spong, and C. Stough, "Neuropsychological sequelae of digital mobile phone exposure in humans," Neuropsychologia, vol. 44, no. 10, pp. 1843-1848, 2006.

[5] L. Lin, "Cataracts and personal communication radiation," IEEE Microwave Magazine, vol. 4, pp. 26-32, 2003.

[6] K.-A. Hossmann and D. M. Hermann, "Effects of electromagnetic radiation of mobile phones on the central nervous system," Bioelectromagnetics, vol. 24, no. 1, pp. 49-62, 2003.

[7] P. Wainwright, "Thermal effects of radiation from cellular telephones," Physics in Medicine and Biology, vol. 45, no. 8, pp. 2363-2372, 2000.

[8] T. Wessapan, S. Srisawatdhisukul, and P. Rattanadecho, "Specific absorption rate and temperature distributions in human 
head subjected to mobile phone radiation at different frequencies," International Journal of Heat and Mass Transfer, vol. 55, no. 1-3, pp. 347-359, 2012.

[9] M. M. Elwassif, Q. Kong, M. Vazquez, and M. Bikson, "Bio-heat transfer model of deep brain stimulation-induced temperature changes," Journal of Neural Engineering, vol. 3, no. 4, article no. 008, 2006.

[10] O. Ley and Y. Bayazitoglu, "Brain temperature distribution during deep hypothermic circulatory arrest in humans," Journal of Mechanics in Medicine and Biology, vol. 04, no. 02, pp. 197212, 2004.

[11] O. Ley and Y. Bayazitoglu, "Effect of physiology on the temperature distribution of a layered head with external convection," International Journal of Heat and Mass Transfer, vol. 46, no. 17, pp. 3233-3241, 2003.

[12] J. Liu, X. Zhang, C. Wang, W. Lu, and Z. Ren, "Generalized time delay bioheat equation and preliminary analysis on its wave nature," Chinese Science Bulletin, vol. 42, no. 4, pp. 289-292, 1997.

[13] F. Xu, T. Lu, and K. A. Seffen, "Dual-Phase-Lag model of skin bioheat transfer," in Proceedings of the BioMedical Engineering and Informatics: New Development and the Future - 1st International Conference on BioMedical Engineering and Informatics, BMEI 2008, pp. 505-511, China, May 2008.

[14] F. Xu, K. A. Seffen, and T. J. Lu, "Non-Fourier analysis of skin biothermomechanics," International Journal of Heat and Mass Transfer, vol. 51, no. 9-10, pp. 2237-2259, 2008.

[15] K. Mitra, S. Kumar, A. Vedavarz, and M. K. Moallemi, "Experimental evidence of hyperbolic heat conduction in processed meat," Journal of Heat Transfer, vol. 117, no. 3, pp. 568-573, 1995.

[16] W.-Q. Lu, J. Liu, and Y. Zeng, "Simulation of the thermal wave propagation in biological tissues by the dual reciprocity boundary element method," Engineering Analysis with Boundary Elements, vol. 22, no. 3, pp. 167-174, 1998.

[17] A. Banerjee, A. A. Ogale, C. Das, K. Mitra, and C. Subramanian, "Temperature distribution in different materials due to short pulse laser irradiation," Heat Transfer Engineering, vol. 26, no. 8, pp. 41-49, 2005.

[18] H. Herwig and K. Beckert, "Fourier versus non-Fourier heat conduction in materials with a nonhomogeneous inner structure," Journal of Heat Transfer, vol. 122, no. 2, pp. 363-365, 2000.

[19] E. P. Scott, M. Tilahun, and B. Vick, "The question of thermal waves in heterogeneous and biological materials," Journal of Biomechanical Engineering, vol. 131, no. 7, Article ID 745181, 2009.

[20] P. J. Antaki, "New interpretation of non-Fourier heat conduction in processed meat," Journal of Heat Transfer, vol. 127, no. 2, pp. 189-193, 2005.

[21] R. Morimoto, A. Hirata, I. Laakso, M. C. Ziskin, and K. R. Foster, "Time constants for temperature elevation in human models exposed to dipole antennas and beams in the frequency range from 1 to $30 \mathrm{GHz}$," Physics in Medicine Biology, vol. 62, no. 5, pp. 10-1088, 2017.

[22] R. Tang, V. Samouillan, J. Dandurand et al., "Thermal and vibrational characterization of human skin: influence of the freezing process," Journal of Thermal Analysis and Calorimetry, vol. 127, no. 2, pp. 1143-1154, 2017. 


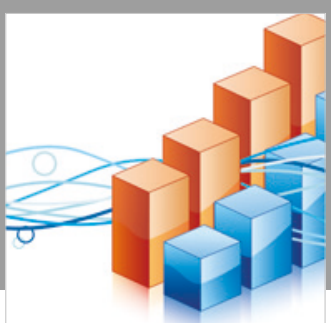

Advances in

Operations Research

\section{-n-m}
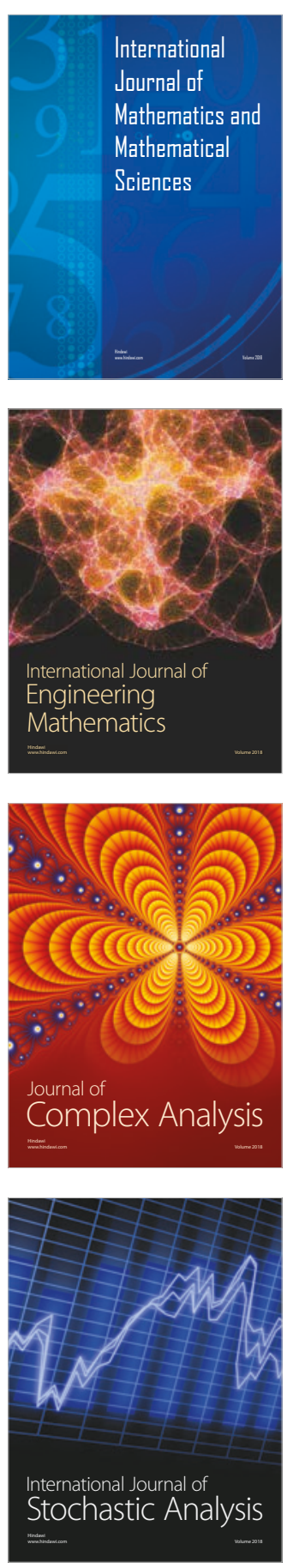
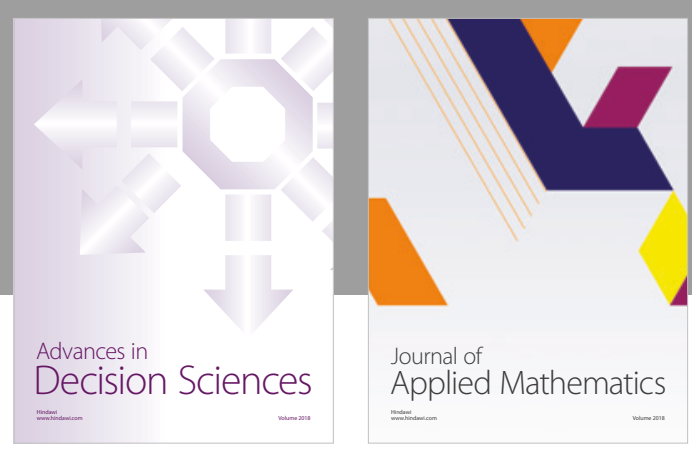

Journal of

Applied Mathematics
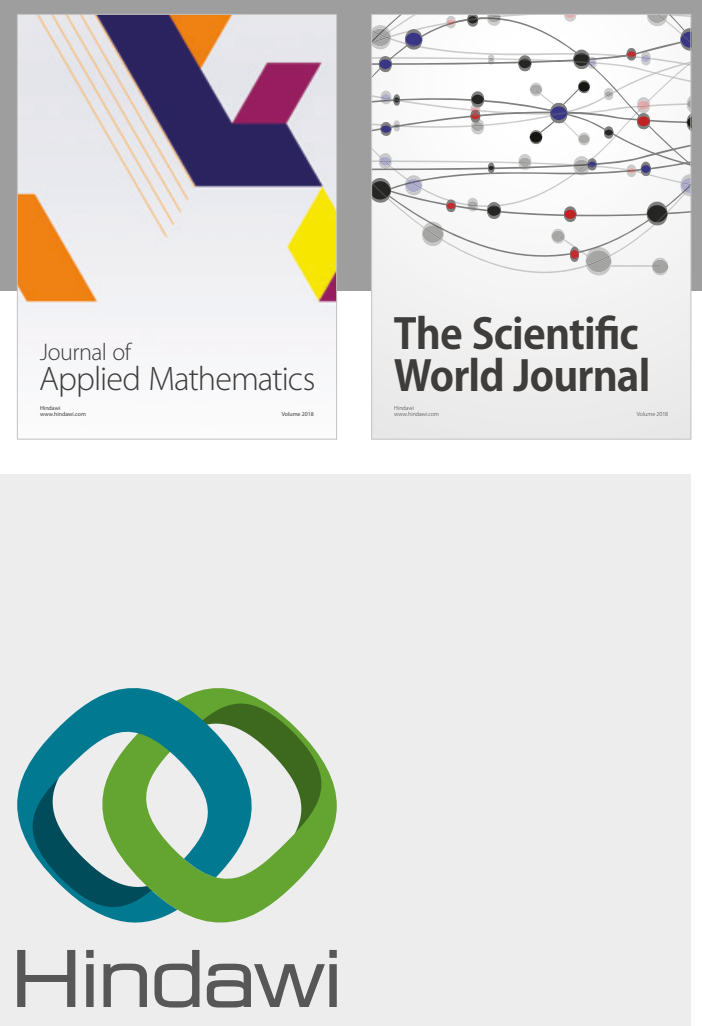

Submit your manuscripts at

www.hindawi.com

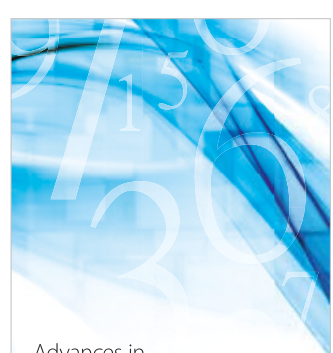

Advances in
Numerical Analysis
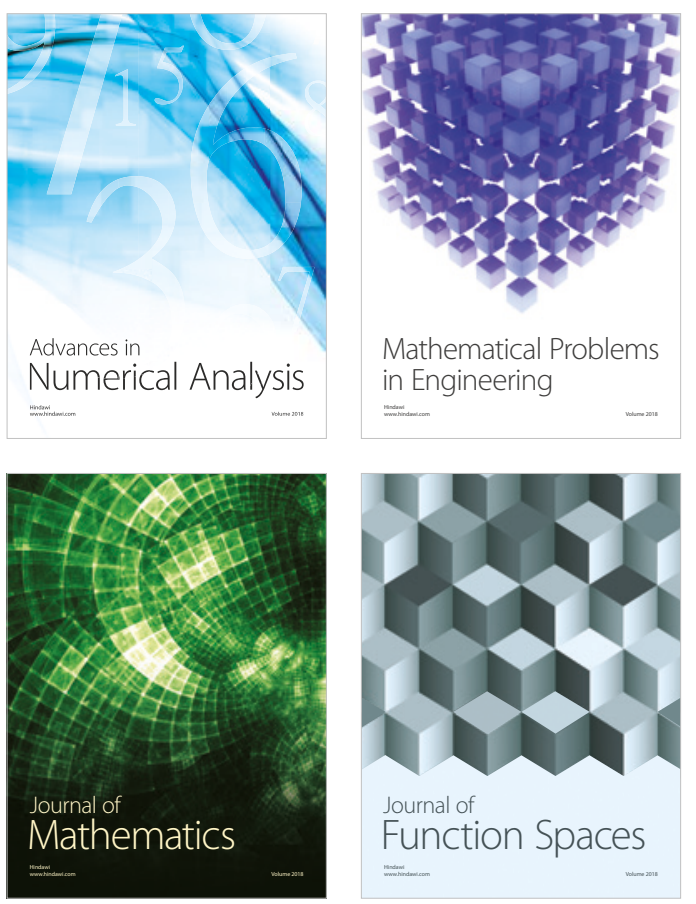

Mathematical Problems in Engineering

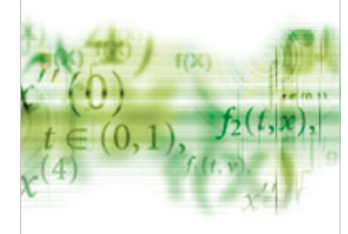

International Journal of

Differential Equations

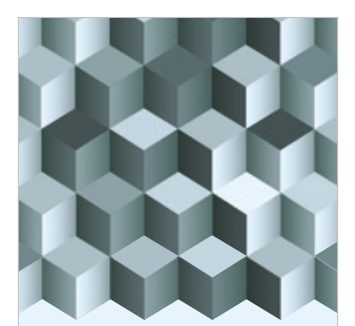

Journal of

Function Spaces

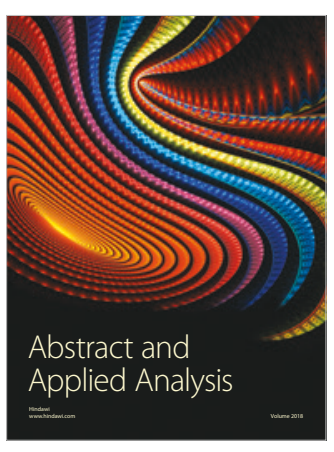

The Scientific

World Journal

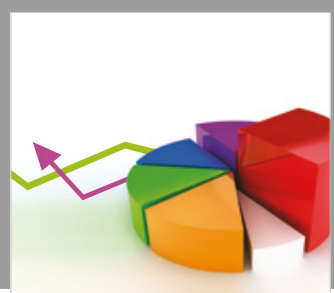

Journal of

Probability and Statistics
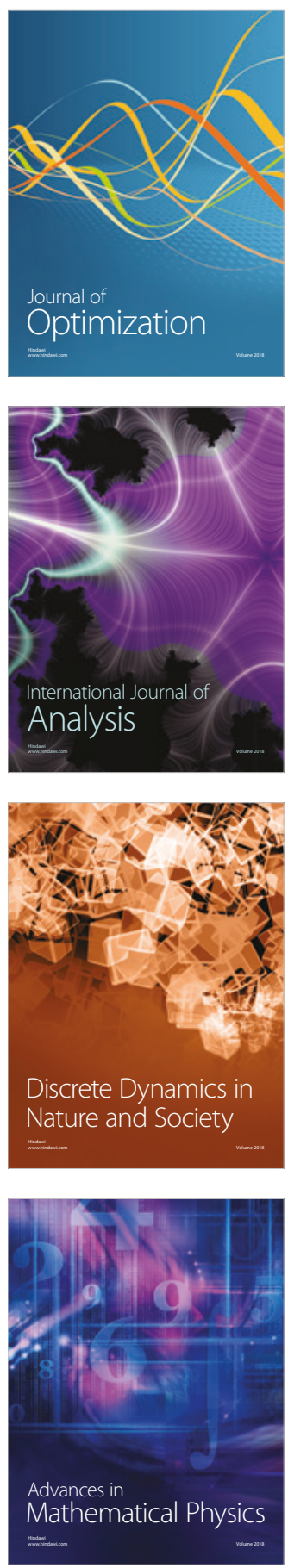